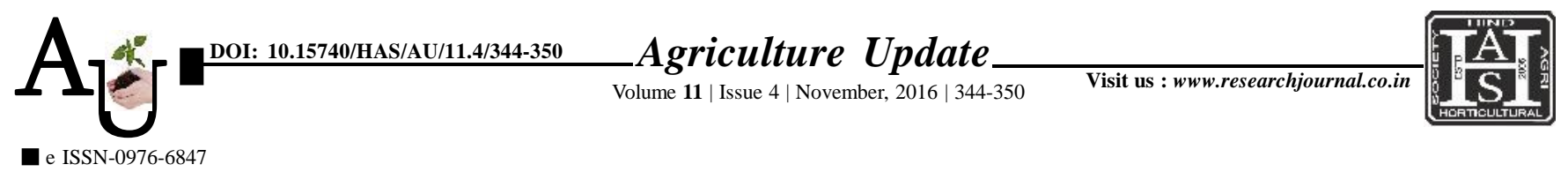

\title{
Research Article: Corollary relationship between entrepreneurial behaviour and other attributes of coriander growers at Ladpura block of Kota district in Rajasthan
}

\author{
口 PRASHANT MARATHA AND S.K. BADODIYA
}

Article Chronicle: Received : 26.08.2016;

Revised :

15.09.2016;

Accepted :

01.10 .2016

KeY Words :

Coriander growers,

Entrepreneurial

behaviour,

Correlation analysis
SUMMARY : Entrepreneurial behaviour of a farmer is influenced by several factors. The study was conducted purposively in Ladpura block of Kota district to assess the entrepreneurial behaviour of coriander growers. The total of 120 coriander growers formed the sample for the study. The primary data were collected through personal interview method with the help of pre-tested interview schedule which was prepared on the basis of objectives of investigation and variables. The statistical tests and procedures were used for analyzing the data. With the help of statistical tools like- mean, S.D., percentage and Karl Pearson's co-efficient of correlation, multiple correlation and regression analysis were used for analysis of data. It is found that majority of the respondents $(55.00 \%)$ had medium level of entrepreneurial behaviour. All the 13 selected attributes of coriander growers, were found positive and significant relationship with entrepreneurial behaviour except age, family size and mass media participation. The major constraints expressed by vegetable growers were fluctuations in the market price $(78.33 \%)$.

How to cite this article : Maratha, Prashant and Badodiya, S.K. (2016). Corollary relationship between entrepreneurial behaviour and other attributes of coriander growers at Ladpura block of Kota district in Rajasthan. Agric. Update, 11(4): 344-350; DOI : 10.15740/HAS/AU/11.4/344-350.
Author for correspondence :

\section{PRASHANT MARATHA}

Rajmata Vijayaraje

Scindia Krishi

Vishwavidyalaya, GWALIOR (M.P.) INDIA

Email:prashantmaratha @ gmail.com

See end of the article for authors' affiliations 